\title{
Anesthesia for awake craniotomy: a how-to guide for the occasional practitioner
}

\section{Anesthésie pour craniotomie éveillé: guide pratique pour le praticien occasionnel}

\author{
Lingzhong Meng, MD • David L. McDonagh, MD • Mitchel S. Berger, MD • \\ Adrian W. Gelb, MBChB
}

Received: 7 August 2016/Revised: 15 December 2016/Accepted: 31 January 2017/Published online: 8 February 2017

(C) Canadian Anesthesiologists' Society 2017

\begin{abstract}
Awake craniotomy (AC), defined as the performance of at least part of an open cranial procedure with the patient awake, has been tied to beneficial outcomes compared with similar surgery under general anesthesia. Improved anesthetic techniques have made a major contribution to the increasing popularity of AC. However, the heterogeneity of practice among institutions doing large numbers of ACs raises questions (often among those who only occasionally perform AC i.e., practitioners in low-volume AC institutions) as to the ideal anesthetic technique for AC. The procedure presents a variety of decision-making dilemmas, the origins of which are the varying institutional preferences, lack of quality evidence, and several practice controversies. Evidence-based data that support a single anesthetic algorithm for AC are sparse. In this narrative review, the technical nuances of 13 aspects of anesthetic care for AC are discussed based on institutional preferences and
\end{abstract}

\footnotetext{
L. Meng, MD ( $\square)$

Department of Anesthesiology, Yale University School of Medicine, 330 Cedar Street, TMP 3, New Haven, CT 06520, USA

e-mail: lingzhong.meng@yale.edu

L. Meng, MD · A. W. Gelb, MBChB

Department of Anesthesia and Perioperative Care, University of California San Francisco, San Francisco, CA, USA
}

D. L. McDonagh, MD

Departments of Anesthesiology \& Pain Management, Neurological Surgery, Neurology \& Neurotherapeutics, UT Southwestern Medical Center, Dallas, TX, USA

M. S. Berger, MD

Department of Neurological Surgery, University of California San Francisco, San Francisco, CA, USA available evidence, and the various controversies and research priorities are discussed. The skills, experience, and commitment of both the surgeon and the anesthesiologist are large variables that are likely more important than what the literature suggests about "best" techniques for AC. Optimizing patient outcome is the fundamental goal of the anesthesiologist.

Résumé La craniotomie éveillé (CE), définie comme la réalisation - au moins en partie - d'une procédure crânienne ouverte alors que le patient est éveillé, a été associée à des résultats favorables, comparativement à la même intervention pratiquée sous anesthésie générale. L'amélioration des techniques anesthésiques a largement contribué à rendre la CE plus populaire. Cependant, l'hétérogénéité des pratiques entre les établissements pratiquant de grands nombres de CE soulève des questions (souvent parmi ceux qui n'en font que rarement, c'est-à-dire, les praticiens exerçant dans des établissements à faibles volumes de CE) autour de la technique anesthésique idéale pour cette intervention. La procédure présente un certain nombre de prises de décision délicates dont les origines tiennent aux préférences des différents établissements, au manque de qualité des données probantes et à plusieurs controverses sur la pratique. Les données probantes reposant sur des preuves et en faveur d'un algorithme anesthésique unique pour la CE sont rares. Dans cette étude narrative, les nuances techniques de 13 aspects des soins anesthésiques pour CE sont discutées en fonction des préférences des établissements et des données probantes disponibles; les différentes controverses et les priorités en matière de recherche sont également discutées. Les compétences, l'expérience et l'engagement du chirurgien et de 
l'anesthésiologiste sont de grandes variables qui sont susceptibles d'être plus importantes que ne le suggère la littérature sur les "meilleures" techniques pour la CE. L'optimisation des résultats pour les patients est l'objectif fondamental de l'anesthésiologiste.

Awake craniotomy (AC) is the performance of at least part of an open intracranial procedure with the patient awake. The first AC was performed in London, UK, on May 25, 1886 when Sir Victor Horsley, then a 29 -yr-old surgeon, resected an epileptogenic lesion from a 22 -yr-old man. ${ }^{1}$ Subsequently, other pioneers, led by Wilder Penfield in Canada, popularized the concept of AC through the first half of the 20th century. ${ }^{2,3}$ During the late 1980s, AC became an important treatment approach - and the standard of care in the eyes of some experts ${ }^{4-6}$ - for brain tumours (primarily gliomas) that are in close proximity to or reside within the eloquent brain (i.e., sensorimotor or language areas)..$^{4-9}$

Accumulating evidence suggests that, compared with surgery under general anesthesia (GA), AC is associated with improved outcomes, including greater extent of tumour resection, ${ }^{8,10}$ fewer late neurological deficits, ${ }^{8,10}$ shorter hospital stay, ${ }^{6,11}$ and longer survival, ${ }^{8}$ especially after brain tumour resection. The improvements in anesthetic care have made a major contribution to the success of modern AC, and a variety of anesthetic techniques have been reported and summarized. ${ }^{6,12-43}$

For the anesthesiologist from an institution that performs a small volume of AC cases, questions often arise as to the ideal anesthetic technique for this procedure. This same question is valid for an experienced anesthesiologist from a high-volume AC centre. For example, the comparative efficacy of GA using a laryngeal mask airway (LMA) compared with monitored anesthesia care (MAC), with the patient lightly to moderately sedated during the pre-awake phase of $\mathrm{AC}$, is a subject that is frequently raised but not yet settled in an evidence-based manner. ${ }^{44,45}$ Therefore, with the aim of optimizing individual patient outcomes, we specifically discuss the preferences, evidence, and controversies of the various anesthetic aspects for AC to further improve the quality of perioperative care for this unique neurosurgical treatment approach.

A total of 13 anesthetic aspects of AC were chosen for this review. Our aim was to discuss the technical nuances of each aspect based on both institutional preferences and the available evidence. The various controversies and research priorities of $\mathrm{AC}$ are also discussed.

\section{Preoperative care}

Patient selection: the non-surgical contraindications

At present, there is little consensus on the non-surgical contraindications for AC, with one physician's indication sometimes another's contraindication. For example, there are reports of $\mathrm{AC}$ being done in patients having serious medical conditions, such as chronic heart failure (with an estimated ejection fraction of $10 \%)^{46}$ or a third-trimester twin pregnancy with the parturient in a looming neurological crisis. $^{47}$ The age of patients who have undergone $\mathrm{AC}$ also varies widely. Indeed, one report documented the perioperative course of a nine-year-old boy - probably the youngest patient on record - who underwent $\mathrm{AC}$ to resect a recurrent high-grade glioblastoma. ${ }^{48}$ Programs at the University of California San Francisco and Toronto Western Hospital have reported age ranges of 13-83 $\mathrm{yr}(n=611 \text { patients })^{6}$ and 12-90 yr $(n=$ 610 patients), ${ }^{7}$ respectively. Overall, patient refusal is arguably the only absolute non-surgical contraindication to AC. Other non-surgical factors - claustrophobia, uncontrolled coughing, inability to remain still, extremely young age, morbid obesity, cognitive disorders (e.g., dementia, Down's syndrome), mood instability - should be regarded as relative contraindications.

Importance of good patient rapport

The path to successful AC begins with the preoperative patient interview. Compared with surgery under GA, the preoperative interview is a particularly important step. Gaining the patient's trust aids in mitigating anxiety and facilitates the constant face-to-face interactions between the patient and caregivers that are needed during the awake phase of surgery. Explanations of why and why not to undergo $\mathrm{AC}$ enhances the patient's engagement. Prior to surgery, the perioperative team, including surgeon, anesthesiologist, and nurse, should visit, introduce themselves, answer questions, and establish a rapport with the patient. Details including positioning, urinary catheter placement, and noise related to craniectomy, amongst other subjects, should be carefully explained. The preoperative visit also allows an opportunity for patients to rehearse the various mapping-related tasks with neurophysiologists before surgery. Obtaining some personal patient details that can serve as topics of conversation (e.g., an interest in sports or travel) during the awake phase can be useful. Reassurance and empathy facilitate the establishment of good patient rapport. The fact that the anesthesiologist is always within hearing range 
and usually visible to the patient should be emphasized, as well as the team's familiarity with caring for patients during the procedure.

\section{Premedications}

Some institutions routinely administer anticonvulsants and corticosteroids before surgery, whereas others, if the indication for $\mathrm{AC}$ is epilepsy, for example, withhold anticonvulsants to facilitate cortical mapping. Medications (e.g., midazolam, fentanyl, atropine, scopolamine) that have the potential to impair neurocognitive function or contribute to emergence confusion/delirium during the intraoperative wake-up should be avoided (Table 1). ${ }^{24,50-52}$ That said, some practitioners would consider giving small doses of midazolam to highly anxious younger patients who have good preoperative neurologic function.

\section{Intraoperative care}

Intraoperative care can be divided into three sequential phases based on how the anesthesia is managed: pre-awake phase, awake phase, post-awake phase. The following discussion is laid out based on this sequence of events.

\section{Patient monitoring}

Standard patient monitors - electrocardiography, blood pressure, pulse oximetry, capnography, temperature should be applied. ${ }^{53}$ Some institutions routinely place an intra-arterial catheter to monitor blood pressure, whereas others rely only on non-invasive blood pressure measurements. Consideration should be given to placing the blood pressure monitor on the arm that is ipsilateral to the brain lesion so as not to interfere with the sensorimotor monitoring of the arm that is contralateral to the brain lesion. This should be done similarly with the pulse oximetry probe - i.e., placing it on the finger or toe that is ipsilateral to the brain lesion to prevent the oximetry cable from limiting the range of motion of the arm that is contralateral to the brain lesion. If it is on the contralateral arm, the intra-arterial and intravenous catheters can be secured with transparent dressings to allow detection of any subtle motor responses that might otherwise be obscured under dressings. These choices, however, are clearly institutional preferences. End-tidal carbon dioxide $\left(\mathrm{EtCO}_{2}\right)$ should be monitored via the sampling channel integrated into nasal cannula tubing (i.e., a specially designed or modified conventional cannula) or connected to the breathing circuit, depending on the method of airway management. The respiratory rate but not the $\mathrm{EtCO}_{2}$ can also be monitored using breathing cycle-induced electrocardiogram variation integrated into many standard monitoring platforms. Placement of an urinary catheter is facilitated by intravenous sedation and intra-urethral lidocaine application. Urethral lidocaine (e.g., URO-Jet ${ }^{\circledR}$, Amphastar Pharmaceuticals, Inc., Rancho Cucamonga, CA, USA) is important for minimizing catheter-related urinary irritation, which is a common cause of intraoperative discomfort.

Intraoperative language and sensorimotor mapping is normally tasked to a trained neurophysiologist and regarded as a surgical aspect of AC. The use of intraoperative stimulation mapping is one of the core components of AC and, based on a meta-analysis of available data, has been associated with fewer late severe

Table 1 Medications reported for use before awake craniotomy

\begin{tabular}{|c|c|}
\hline Premedication & Comment* \\
\hline Anticonvulsants (e.g., levetiracetam) & Frequently administered to reduce the chance of perioperative seizure \\
\hline Steroids (e.g. dexamethasone) & Normally administered to reduce peri-tumor edema \\
\hline 5- $\mathrm{HT}_{3}$ receptor antagonist (e.g., ondansetron) & Nausea/vomiting prophylaxis \\
\hline Neurokinin receptor antagonist (e.g., aprepitant) & Nausea/vomiting prophylaxis \\
\hline Benzodiazepines (e.g., midazolam) & $\begin{array}{l}\text { May adversely affect neurocognitive function; }{ }^{49} \text { consider only if there is } \\
\text { intractable anxiety }\end{array}$ \\
\hline Opioids (e.g., fentanyl) & May cause nausea, itchy nose and dizziness; consider only if there is intractable pain \\
\hline Anticholinergic (e.g., atropine or scopolamine) & May cause dry mouth and emergence delirium; not recommended \\
\hline NSAIDs (e.g., acetaminophen) & Oral or $i v$ acetaminophen can be a useful analgesic adjunct \\
\hline Antacids (e.g., famotidine) & May consider if gastroesophageal reflux disease \\
\hline Metoclopramide & Possesses unwarranted neurologic effect, may cause dystonic reactions; not recommended \\
\hline Droperidol & $\begin{array}{l}\text { Previously used for neuroleptanalgesic anesthesia, may impede neurocognitive testing; not } \\
\text { recommended }\end{array}$ \\
\hline Clonidine & May cause hypotension and long-lasting sedation; not recommended \\
\hline
\end{tabular}

*Based largely on authors' institutional preferences. NSAIDs = non-steroidal anti-inflammatory drugs. 
neurologic deficits and more extensive tumour resection. ${ }^{10}$ Some institutions use electrocorticography (i.e., brain electrical activity recorded directly from the cortex) to detect epileptiform activity and warn the surgeon of stimulation-induced after-discharge activity (as an indication of excessive stimulation current). ${ }^{6}$ Phase reversal of somatosensory evoked potentials can be used to identify the central sulcus during the pre-awake phase, although it is not typically used in an awake patient. Heterogeneity exists in the use of intraoperative stimulation mapping and neurophysiological monitoring techniques. The technical details of intraoperative mapping can be found in other published reports. ${ }^{4-6}$

Patient positioning and the operating room bed

The operating room bed is typically turned $90^{\circ}$ (in reference to the anesthesia workstation) to either left or right depending on the side of the brain lesion. This maneuver positions the patient facing the anesthesia workstation, which makes the face-to-face interaction during the awake phase convenient and facilitates any airway management, if needed.

The patient can be positioned supine - laterally on an axillary roll or semi-laterally with the back of the patient resting on a round longitudinal pillow. The semi-lateral position is preferred by some institutions because it enhances the patient's positional endurance, facilitates surgical access to the lesion side of the brain, and makes direct face-to-face or face-to-screen interaction possible (Fig. 1A-D). It also facilitates spontaneous ventilation by enhancing chest compliance in a patient with an obese abdomen. An axillary roll can be used in the lateral position but is normally not needed for the semi-lateral position.

Most institutions secure the patient's head in a pinned head frame after infiltrating the pin sites with local anesthetics. A small number of institutions simply support the head on a horseshoe frame or its equivalent. Using a pinned head frame prevents the head from moving, but it makes manipulation of the head/neck position during airway emergency difficult and has the potential risk of lacerating the scalp. In contrast, the use of horseshoe support facilitates head/neck re-positioning during airway management, although the patient may unintentionally move the head, causing safety and sterilization concerns. A minor turn of the patient's head (away from the lesion side) is frequently applied for the semi-lateral patient to facilitate surgical access. It is usually well tolerated by the patient. A "sniffing" position for the head and neck (mild head extension and anterior translocation) aids in optimizing airway patency prior to securing the head frame to the operating room bed at the start of the procedure.
Airway management during the pre-awake phase

Various techniques of airway management during the preawake phase of AC have been described. The GA-awakeGA (a.k.a. asleep-awake-asleep, or AAA) technique with an endotracheal tube (ETT) placed before and after the awake phase was originally described in $1998 .{ }^{17}$ A small tube exchanger may be left endotracheally after extubation to facilitate reintubation. This technique is laborious and is prone to complications with inexperienced practitioners. The tube exchanger left in the trachea for reintubation can affect intraoperative language testing. An alternative to the traditional AAA technique using an ETT is to use an LMA during the pre-awake phase, remove the LMA during the awake phase, and finish the case without the LMA during the post-awake phase. Even though the LMA offers some airway control, it does not guarantee satisfactory controlled ventilation. Ineffective ventilation due to a malpositioned LMA-related air leak, which can occur in a semi-laterally positioned patient when the head is slightly rotated, can cause undesired hypercapnia. Some institutions use unilateral or bilateral nasopharyngeal airways (nasal trumpet) attached to the breathing circuit in patients who are spontaneously breathing but deeply sedated. ${ }^{43}$ The disadvantage to this approach, although feasible, is the difficulty/inability to apply positive-pressure ventilation to control $\mathrm{PaCO}_{2}{ }^{28}$

A distinctive approach to airway management during AC is avoidance of an LMA or ETT altogether - proceeding with the pre-awake phase of AC under light to moderate sedation. In this case, a nasal cannula (taped to both cheeks), with an $\mathrm{EtCO}_{2}$ sampling channel, is used for supplemental oxygen and monitoring respiration. Although a nasopharyngeal or oropharyngeal airway is normally not needed, it can be placed when necessary, facilitated by propofol sedation and lidocaine paste. A drawback of this approach is hypercapnia due to airway obstruction or hypoventilation, especially when higher doses of propofol and/or remifentanil are used. If airway obstruction or hypoventilation develops, one can either add dexmedetomidine to minimize the dose of propofol or remifentanil, or stop sedative infusions altogether to awaken the patient.

The superiority of any one technique for airway management during the pre-awake phase of $\mathrm{AC}$ is unknown because of the lack of comparative studies.

General anesthesia vs light to moderate sedation during the pre-awake phase

We define the patient as being under GA when an LMA or ETT is placed or when the patient is deeply sedated without an LMA or ETT. Otherwise, the patient is regarded as being under light to moderate sedation (MAC). The 
Fig. 1 Semi-lateral position for awake craniotomy (A) with the surgeon's view (B), the anesthesiologist's view (C), and the operating room layout (D) shown. The body side (i.e., ipsilateral side) of the hemisphere with the lesion is the side that is up and supported by a round longitudinal bolster from shoulder to buttock. The upper leg is elevated with padding. The hip and knee of the lower leg can flex slightly for comfort. The upper arm rests on the chest and abdomen. The lower arm rests on an arm board with the angle between arm board and operating table adjusted to patient's comfort. The patient's head can be slightly rotated to facilitate surgeon's access without causing patient discomfort. A right-angled bar is attached to the head of the table as a mechanism to tent the surgical drape upward and open the space in front of patient's face via which the patient can see the testing screen on the side, and the caregivers can reach in to help the patient
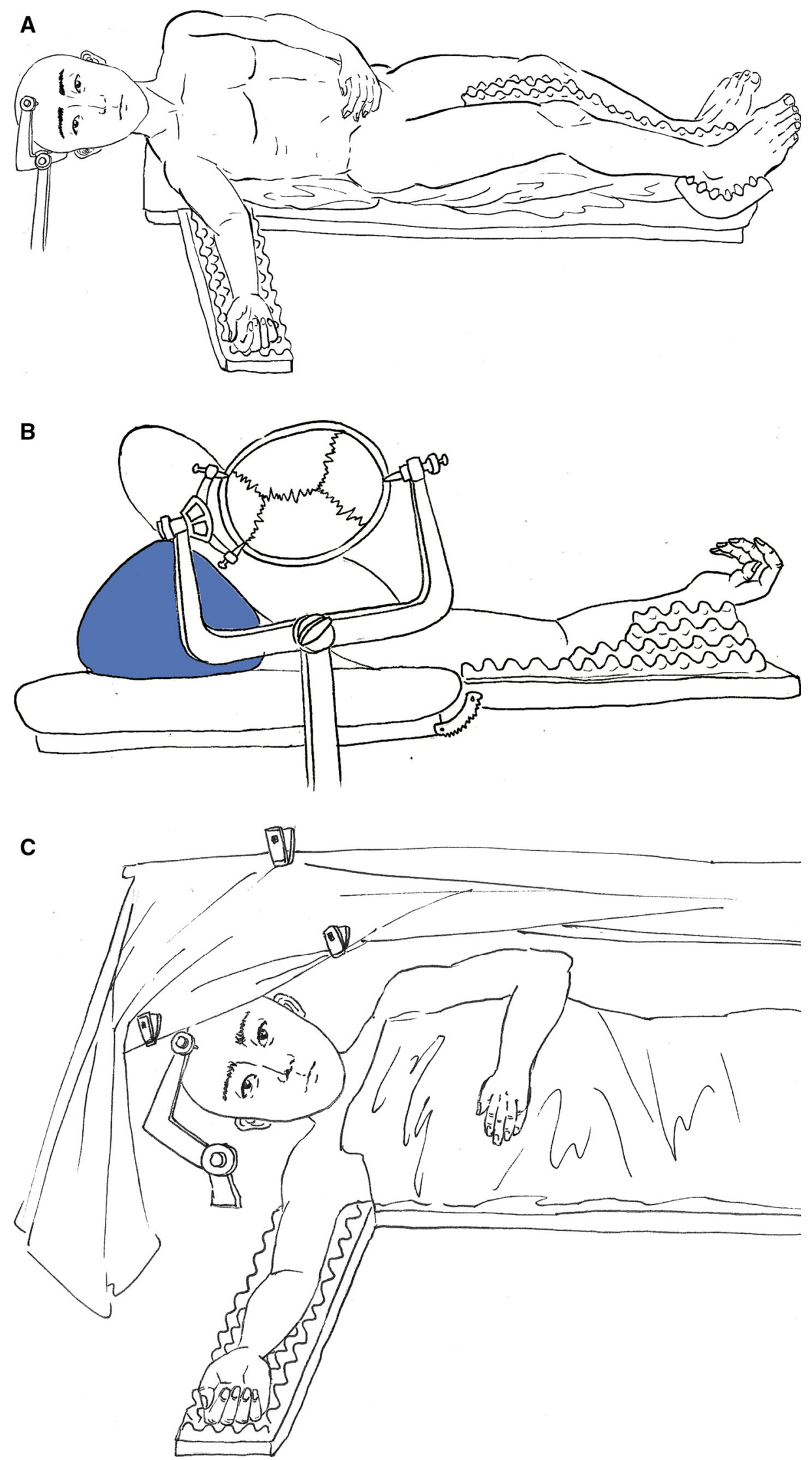
Fig. 1 continued

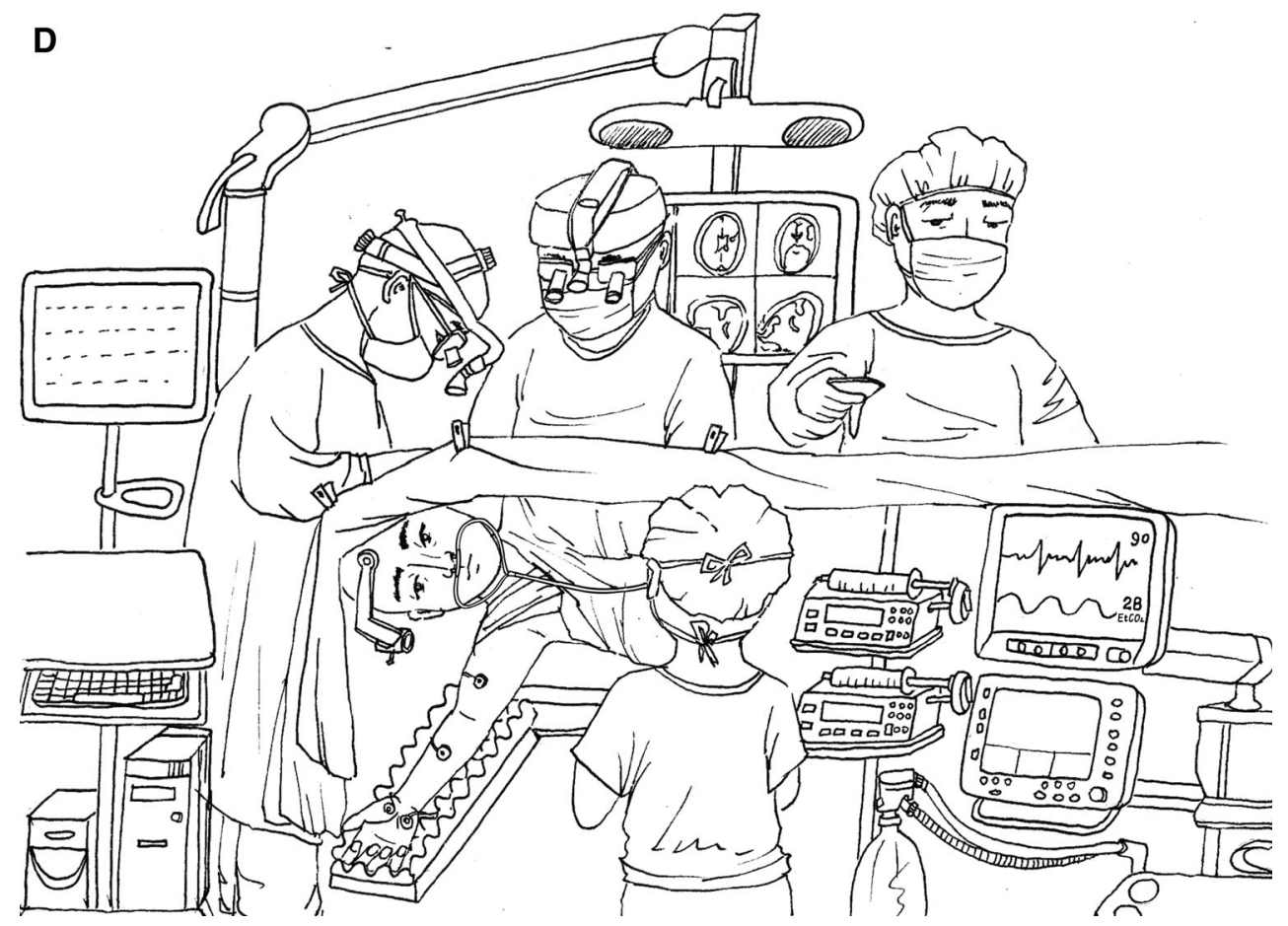

advantages of GA include better airway control (if using an LMA or ETT) and a motionless patient. The potential drawbacks include, but are not limited to, (1) lengthy, unpredictable asleep-to-awake transition, (2) emergence drowsiness, and (3) emergence confusion/delirium - with the risk of inflicting self-injury or jeopardizing meaningful awake testing. Potential disadvantages of light to moderate sedation for the pre-awake phase include movement, talkativeness, and anxiety. The transition to being fully awake, however, is much faster, more predictable, and less problematic.

It has been argued that the avoidance of GA-related physiological disturbances, mechanical ventilation, and potential anti-tumour immunity suppression might contribute to the beneficial outcomes associated with AC, when compared with surgery under GA, ${ }^{54}$ although the validity of this proposition remains highly speculative. Nonetheless, an important distinction is needed here (Fig. 2). For craniotomy under GA, the anesthetic is applied throughout the procedure, whereas with conventional AC using an LMA the patient is exposed to GA only during the pre-awake phase. Therefore, the duration of GA for AC is much shorter than that for surgery performed completely under GA (i.e., $\sim 1-2 \mathrm{hr} v s \sim 4-5$ $\mathrm{hr}$ ). This is different from the scenario where the pre-awake phase of AC is performed under light to moderate sedation, and the patient is never exposed to GA. The impact of GA $v s$ light to moderate sedation on outcomes in this setting is unknown. It appears that the major institutions that perform

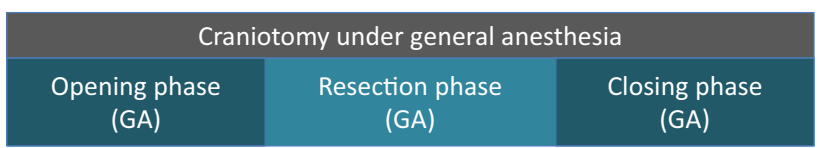

\begin{tabular}{|c|c|c|}
\hline \multicolumn{3}{|c|}{ Awake craniotomy } \\
\hline $\begin{array}{l}\text { Pre-awake phase } \\
\text { (GA/ETT) }\end{array}$ & Awake phase & $\begin{array}{l}\text { Post-awake phase } \\
\text { (GA/ETT) }\end{array}$ \\
\hline $\begin{array}{l}\text { Pre-awake phase } \\
\text { (GA/LMA) }\end{array}$ & Awake phase & $\begin{array}{l}\text { Post-awake phase } \\
\text { (MAC) }\end{array}$ \\
\hline $\begin{array}{l}\text { Pre-awake phase } \\
\text { (MAC) }\end{array}$ & Awake phase & $\begin{array}{l}\text { Post-awake phase } \\
\text { (MAC) }\end{array}$ \\
\hline
\end{tabular}

Fig. 2 Comparison between craniotomy under general anesthesia (GA) and awake craniotomy. Both surgical approaches are arbitrarily divided into three phases. For craniotomy under GA, the GA is applied throughout all three phases. For awake craniotomy, the anesthetic technique during the pre-awake phase varies: GA with endotracheal tube (ETT) vs GA with laryngeal mask airway (LMA) vs monitored anesthesia care (MAC). There is no or minimal sedation/ analgesia during the awake phase. Currently, MAC is the most popular anesthetic technique used during the post-awake phase

$\mathrm{AC}$ are split on their preferences - some prefer a sedation level that renders the patient drowsy but readily arousable and others prefer GA with an LMA.

Local anesthesia for analgesia

The mainstay of analgesia during AC is local anesthesia via either field infiltration or scalp nerve block (typically using 
$\sim 40-60 \mathrm{~mL}$ of $0.25 \%$ bupivacaine mixed with $1 \%$ lidocaine [50:50] and 1:100,000 epinephrine). ${ }^{6,55,56}$ Field infiltration and scalp nerve block are distinct approaches. Some institutions rely solely on field infiltration, whereas others combine field infiltration (primary modality) with scalp nerve blocks as adjuncts. The efficacy of field infiltration for controlling surgical pain during craniotomy has been verified by both clinical experience and previous studies. ${ }^{57,58}$ Some studies, however, suggest that the analgesic efficacy of scalp nerve block is similar to that of field infiltration for AC (as well as for craniotomy under GA). ${ }^{56,59}$ Therefore, it is likely that, in experienced hands, field infiltration and scalp nerve block are alternative local anesthetic techniques. With adequate local anesthesia, intravenous opioid administration is rarely needed during AC. Subsequent injection of additional local anesthetics into the incision site (including the dura) and across the scalp flap is usually effective in relieving new-onset pain that occurs during the surgery. According to the results of some laboratory and retrospective studies, other advantages attributable to local anesthetics include a neutral neurocognitive effect and potential tumour-suppressive effects. $^{60-66}$ There is currently no consensus on the choice or dose of local anesthetics for AC. Exuberant application of local anesthetics has the potential to cause seizures and other toxicities, ${ }^{67}$ as well as hypertension in the case of inadvertent intravascular epinephrine injection.

\section{Agents for sedation and GA}

It is enlightening to revisit the evolution of anesthetic regimens for AC, especially the story of the rise and fall of each drug. What Horsley used in his AC patients was a combination of morphine and chloroform, with the chloroform discontinued during the case to awaken the patient. Indeed, he noted that "...I have been very deeply impressed with the startling rapidity with which a patient who has roused up in the middle of the operation...." ${ }^{1}$ The advent of local anesthetics and their application in neurosurgical patients revolutionized the practice of $\mathrm{AC}$ during the first half of the 20th century. ${ }^{3,9,29,55}$ The concept of neuroleptanesthesia (i.e., a state produced by the combined administration of a potent neuroleptic and narcotic drugs), ${ }^{68}$ introduced by De Castro and Mundeleer in 1959, opened an era of using a standardized sedation protocol consisting of droperidol and fentanyl for $\mathrm{AC}$ that continued for more than three decades. ${ }^{12}$ In 1988, Archer et al. reported their experience with droperidol and fentanyl neuroleptanesthesia in 354 consecutive awake cases and found no perioperative morbidity or mortality that could be attributed to anesthesia. $^{14}$ In 1992, Silbergeld et al. reported their usage of propofol for AC. ${ }^{15}$ Since then, drugs featuring rapid onset and offset, titratability, and minimal lingering neurocognitive effects have become the mainstay for sedation during AC (predominantly propofol and remifentanil). ${ }^{16,18-23,28,34,37,51,52}$ The Chinese experience of using acupuncture as the mainstay of anesthesia/ analgesia supplemented by meperidine and haloperidol (or droperidol) for $\mathrm{AC}$, with the first case performed in 1965 , is an intriguing approach to minimize the use of the drugs and their various adverse effects. ${ }^{13}$ Entering the $21 \mathrm{st}$ century, the introduction of dexmedetomidine in $\mathrm{AC}$ reflects its unique advantages of causing minimal respiratory depression while providing sedation and some analgesic effect. $^{25-27,30,41}$

An ideal drug for AC should possess such attributes as fast onset/offset, minimal lingering neurological effect after termination, and no depressive cardiovascular or respiratory effects. It should also benefit disease-specific outcomes, similar to the advantageous oncological effect (i.e., lower incidence of recurrence and metastasis and longer survival) that has been suggested, albeit lacking convincing data, for propofol anesthesia. ${ }^{69-80}$ Unfortunately, there is currently no such magic bullet. Every modern anesthetic drug used for $\mathrm{AC}$ is a double-edged sword. Different patients may have differing sensitivities to the same drug. Moreover, the drug effect is almost always dose dependent. It is advisable not to put forward an invariable protocol but to advocate a flexible approach based on the needs and response of the individual patient. $^{6}$

A recent retrospective study correlated the use of inhalational anesthesia, compared with intravenous anesthesia, with worse survival in cancer patients, although the study was not specifically done on brain tumour patients. ${ }^{69}$ If a cause-effect relation between the choice of anesthetic agents and cancer patient survival is eventually proven in prospective randomized controlled trials, the anesthetic regimens for awake brain tumour surgery and any oncological surgery requiring anesthetic care must be re-considered.

A frequently used sedative regimen for AC is low-dose propofol $\left(20-50 \mu \mathrm{g} \cdot \mathrm{kg}^{-1} \cdot \mathrm{min}^{-1}\right.$ and remifentanil (0.01$\left.0.06 \mu \mathrm{g} \cdot \mathrm{kg}^{-1} \cdot \mathrm{min}^{-1}\right)$ infusions titrated to make the patient drowsy but arousable - and without airway obstruction. Remifentanil, albeit a narcotic, is chosen because it is easily titratable, acts as a potent sedative (i.e., maintaining a calm patient), and causes fewer gastrointestinal side effects than fentanyl. ${ }^{81}$ Some institutions use dexmedetomidine $\left(0.3-0.5 \mu \mathrm{g} \cdot \mathrm{kg}^{-1} \cdot \mathrm{hr}^{-1}\right)$ as an adjunct when the patient cannot be satisfactorily sedated by propofol and remifentanil infusion or when airway obstruction or hypoventilation mandates reduction or cessation of propofol or remifentanil. The satisfactory application of dexmedetomidine as a sole sedative agent for $\mathrm{AC}$ has also been reported. ${ }^{30,82}$ The sedation provided 
by propofol, remifentanil, or dexmedetomidine does not appear to interfere with electrocorticography during AC. ${ }^{16,18,23,30}$ If an LMA is used, a combination of intravenous infusions (propofol $\sim 50-100 \mu \mathrm{g}^{-1} \cdot \mathrm{min}^{-1}$ and remifentanil $\sim 0.1-0.2 \mu \mathrm{g} \cdot \mathrm{kg}^{-1} \cdot \mathrm{min}^{-1}$ ) and/or inhalational agents (sevoflurane or desflurane $<0.5$ minimum alveolar concentration along with remifentanil $\sim 0.1-0.2$ $\mu \mathrm{g} \cdot \mathrm{kg}^{-1} \cdot \mathrm{min}^{-1}$ ) is frequently used to effect a rapid transition from asleep to awake with clear headedness.

\section{Awake phase}

If a deep plane of sedation or GA is used during the preawake stage, preparedness for awakening the patient should be started as early as possible. The surgeon normally gives a time estimate for awakening the patient. All sedative or hypnotic agents are typically discontinued at the moment the bone flap is removed unless some asleep cortical mapping is desired. The goal is to awaken the patient smoothly and rapidly without agitation, confusion, or drowsiness. Some anesthesiologists keep the remifentanil infusion going at a low rate $(\sim 0.01-0.05$ $\left.\mu \mathrm{g} \cdot \mathrm{kg}^{-1} \cdot \mathrm{min}^{-1}\right)$ to facilitate a smooth transition and provide some analgesia during the awake phase.

The goal during the awake phase is to have the patient engaged, cooperative, pain-free, and comfortable. A swab soaked with ice-cold water can be used to wet the patient's lips and mouth for comfort. Similarly, ice chips work well to optimize patient comfort and offer a temporary distraction as they chew or suck the chips. Patients frequently need help to scratch the skin around the nostrils and the inner canthus/corner of the eyes for opioid-related itching. Most patients ask to move their hips/ legs/arms because of positional discomfort. It is important to instruct the patient not to move the head and shoulders when making positional adjustments. The room temperature should be adjusted for the patient's comfort. An air blanket can be used as needed to provide either warm or cool air. Empathy, hand-holding, and reassurance offer great support to patients and should always be provided during the awake phase. Ongoing encouragement, coaching, and conversation are essential. Finally, keep in mind that bilingual patients may need bilingual language testing as language function for the primary language may not entirely overlap the secondary language. ${ }^{83}$

Emergence agitation and delirium can ensue on awakening, especially if the pre-awake phase is done under GA or deep sedation, and can be dangerous to the patient and extremely difficult to manage. At this time, there is no consensus on effective management. Nevertheless, the following strategies can be used. The first step is to "re-induce" anesthesia with a propofol bolus (30-50 mg) while avoiding apnea. Dexmedetomidine boluses of $\sim 0.1-0.2 \mu \mathrm{g} \cdot \mathrm{kg}^{-1}$ can be given prior to the second wake-up attempt. A physostigmine bolus (0.5-1.0 $\mathrm{mg}$ ) can also be used to ablate emergence delirium, although evidence to support its use is weak. ${ }^{84,85} \mathrm{~A}$ remifentanil infusion can be continued at a low rate ( 0.01-0.05 $\mu \mathrm{g} \cdot \mathrm{kg}^{-1} \cdot \mathrm{min}^{-1}$ ) during the re-awakening to help with behavioral control. Finally, droperidol or haloperidol can be administered prior to the re-awakening (with awareness of the potential QT-prolonging effects).

Unfortunately, most of these medications have the potential to impact immediate neurocognitive function adversely, so a risk-benefit assessment is always needed when treating patients with emergence agitation/delirium. Effective prevention for emergence agitation and delirium is unproven. It is prudent to minimize sedation in high-risk patients (e.g., those with baseline cognitive dysfunction) or choose drugs characterized by rapid offset and minimal lingering effect.

Somnolence on emergence leaves the anesthesiologist with many fewer management options. Intravenous caffeine is an option but has undefined efficacy. ${ }^{86}$ Dexmedetomidine is the only relatively longer-acting sedative typically used for AC - i.e., it cannot be "taken away" or reversed if the patient is slow to emerge into the awake phase. Elderly patients seem particularly sensitive, ${ }^{87}$ so great caution should be exercised with dexmedetomidine in these cases. Similarly, midazolam should be avoided in elderly patients, especially those with impaired hepatic or kidney function. Residual opioid effects can be reversed with naloxone (40-120 $\mu \mathrm{g} i v$, repeated as needed).

\section{Managing intraoperative complications}

Imminent potential complications during $\mathrm{AC}$ that require life-saving intervention are seizures and airway emergencies. The reported incidence of intraoperative seizure (type unspecified) ranges from $3 \%$ to $16 \%$ based on case series with more than 300 patients. ${ }^{6,7,14,88,89}$ Seizures frequently occur during cortical and subcortical stimulation mapping. The first line of treatment is irrigation of the cortex with ice-cold crystalloid solution applied by the neurosurgeon (repeated as necessary). ${ }^{6}$ Fortunately, most intraoperative seizures can be stopped by this maneuver. If it is ineffective (i.e., the seizure activity is spreading or generalizing), however, intravenous propofol (30-50 mg) should be administered and repeated as necessary. The patient must be closely watched for seizure recurrence or airway compromise. Most intraoperative seizures are resolved without adverse consequences, although apnea and cardiac arrest can occur. Airway instrumentation is normally not needed. 
When needed, it is often the result of excessive propofol administration.

For an obstructed airway emergency, a rapid differential diagnosis is needed to identify the cause. In parallel, one should alert the surgeon, call for help, stop all infusions, and mask-ventilate the patient with $100 \%$ inspired oxygen with appropriate jaw thrust, perhaps facilitated by an oral or nasal airway. In anticipation of such a life-threatening event, there should always be an LMA, syringe, and lubricant at hand. Some also like to have an ETT and video laryngoscope within reach. An LMA should be placed if mask ventilation fails or if the situation otherwise mandates it. It can be difficult to position an LMA in a semi-lateral patient whose head is slightly turned and secured in a pinned head frame. The tongue can be pulled out using a $4 \times 4^{\prime \prime}$ gauze or Magill forceps to facilitate LMA placement, if needed. The patient can be intubated using a video laryngoscope with the anesthesiologist standing in front of the patient, although it is better done with the assistance of an additional skilled anesthesiologist. Lastly, if the ventilation crisis is due to remifentanil-induced apnea or chest rigidity, one should attempt mask-ventilation while at the same time stopping the remifentanil infusion. These actions may be sufficient to resolve the crisis. Low-dose succinylcholine $\left(\sim 0.5 \mathrm{mg} \cdot \mathrm{kg}^{-1}\right)$ should be used promptly if the crisis (chest rigidity) is not quickly aborted by other measures, although there are no clinical trial data to support this practice.

Table 2 Technical nuances of the various anesthetic aspects for awake craniotomy

\begin{tabular}{|c|c|}
\hline Anesthetic aspects & Key considerations \& messages \\
\hline Decision making & $\begin{array}{l}\text { Patient outcomes including safety, comfort, and disease-specific outcomes, quality of evidence, patient's } \\
\text { preference, provider's expertise, and institutional culture }\end{array}$ \\
\hline Preoperative care & $\begin{array}{l}\text { Visit and establish good rapport with the patient; explain to patient the relevant details of the perioperative } \\
\text { care; answer questions }\end{array}$ \\
\hline Intraoperative phases & Pre-awake phase $>>$ awake phase $>>$ post-awake phase \\
\hline Pre-awake phase & $\begin{array}{l}\text { GA with LMA vs MAC with or without nasopharyngeal airway. Some authors prefer light to moderate MAC } \\
\text { with the patient drowsy but readily arousable }\end{array}$ \\
\hline $\begin{array}{l}\text { Airway management during the } \\
\text { pre-awake phase }\end{array}$ & LMA (GA) vs nasopharyngeal airway (MAC) vs no airway instrumentation (MAC) \\
\hline $\begin{array}{l}\text { GA } v s \text { MAC for the pre-awake } \\
\text { phase }\end{array}$ & $\begin{array}{l}\text { Differ in airway management, ventilation mode (mechanical } v s \text { spontaneous), and physiological disturbances; } \\
\text { may also differ in the impact on anti-tumour immunity, oncological outcomes, and patient's survival } \\
\text { (awaiting evidence) }\end{array}$ \\
\hline $\begin{array}{l}\text { Goals during the asleep-to-awake } \\
\text { transition }\end{array}$ & Smooth and rapid return of the baseline mental status; avoid somnolence, confusion, agitation, and delirium \\
\hline Awake phase & $\begin{array}{l}\text { The goal is to have an engaging, cooperative, pain-free, comfortable patient. No or minimal sedation (e.g., } \\
\text { remifentanil), ice chips/water to wet the lip and mouth, face scratch for itching, position adjustment of } \\
\text { shoulders/hips/legs, supplemental local anesthetic injection for pain (and possibly intravenous } \\
\text { acetaminophen), comfortable room temperature, air blanket for comfort, euvolemia, empathy, and } \\
\text { reassurance }\end{array}$ \\
\hline Airway backup and emergency & $\begin{array}{l}\text { Have a video laryngoscope in room; have an LMA (different sizes) with lubricant and an endotracheal tube } \\
\text { with a stylet handy; have propofol and succinylcholine in syringe. If airway emergency, call for helper, stop } \\
\text { infusions, mask-ventilate (with an oropharyngeal or nasopharyngeal airway), try to place an LMA if no } \\
\text { improvement with mask ventilation (may need to pull the tongue out to facilitate the placement), try to } \\
\text { intubate the patient using video laryngoscope by standing in front of the patient if LMA fails; surgeon to lift } \\
\text { drapes out of the way while preserving sterility }\end{array}$ \\
\hline $\begin{array}{l}\text { Intraoperative seizure \& } \\
\quad \text { neurological complications }\end{array}$ & $\begin{array}{l}\text { Irrigate ice-cold saline solution onto the cortex, small propofol bolus }(30-50 \mathrm{mg}) \text { if needed; think } \mathrm{ABC} \\
\text { (airway, breathing, circulation); supportive if patient recovers; convert to } \mathrm{GA} \text { if necessary; show empathy } \\
\text { and comfort the patient if neurological complications (e.g. worsening weakness or language, paralysis) with } \\
\text { the understanding that some deficits are recoverable }\end{array}$ \\
\hline Post-awake phase & $\begin{array}{l}\text { LMA is normally not replaced even if used during the pre-awake phase. Sedation often suffices, as patients } \\
\text { are often fatigued }\end{array}$ \\
\hline Postoperative care & $\begin{array}{l}\text { Large variation in practice. Decision to admit to ICU, floor, or discharge home on the same day should be } \\
\text { based on patient's condition and institutional experience. Early discharge with a well-established backup } \\
\text { plan is the current trend }\end{array}$ \\
\hline Future research & $\begin{array}{l}\text { Outcome-oriented studies comparing GA vs MAC for the pre-awake phase; prevention and treatment of } \\
\text { emergence confusion/delirium; impacts of different airway management; impact of anesthetic agents on } \\
\text { brain tumor outcomes }\end{array}$ \\
\hline
\end{tabular}

$\mathrm{GA}=$ general anesthesia; $\mathrm{ICU}=$ intensive care unit; LMA = laryngeal mask airway; MAC = monitored anesthesia care 
Post-awake phase

Sedation is normally restarted, and the case can usually be finished without an LMA even if it was used during the pre-awake phase. The patient typically requires lower rates of sedative infusions during the post-awake phase than during the pre-awake phase. This may be due to fatigue from the awake phase, release of the psychological pressure after learning of successful lesion removal, and the lower level of painful stimuli during skull closure compared with that at skull opening. The goal of sedation is to keep the patient drowsy but without airway obstruction.

\section{Postoperative care}

The rapid recovery after AC has revolutionized the subsequent care of these patients. A recent systematic review concluded that $\mathrm{AC}$ is associated with a much shorter hospital stay (four days) than craniotomy under GA (nine days) based on seven comparative studies ( $P$ value unreported). ${ }^{11}$ On average (median), patients are discharged home on day 3 (range days 2-20) after awake brain tumour resection by the program at University of California San Francisco. ${ }^{6}$ The program at Toronto Western Hospital also reported a median three-day hospital stay (range, days 0-47), ${ }^{90}$ with some patients discharged home on the same day of surgery. ${ }^{91,92}$ Most institutions admit the patient to a neuro-intensive care unit for close overnight observation after AC, although others see this as overly conservative. $^{90,91}$ The postoperative visit provides an important opportunity for anesthesia providers to learn from the patient about the parts of the procedure that he or she found most difficult. The short-term outcomes associated with AC, in contrast to those associated with conventional craniotomy under GA, can also be better appreciated with this early postoperative visit.

\section{Research opportunities}

Quality research and evidence can improve patient outcomes via standardization of clinical practice and the resolution of controversial topics. Obvious controversies in the anesthetic care for AC include optimal airway management, the choice of GA vs MAC, deep sedation vs light to moderate sedation, and the choice of anesthetic/sedative agents during the preawake stage. The outcomes of most concern to patients (e.g., tumour recurrence, survival) should be used as the end points of research targeting these controversies. ${ }^{93}$ For example, emergence delirium (assessed shortly after anesthesia) has a high prevalence and has been linked to postoperative delirium (assessed on and after postoperative day 1). ${ }^{94-96}$ Clinically, emergence delirium (hypoactive or hyperactive) following the asleep-to-awake transition during $\mathrm{AC}$ does occur, especially when the pre-awake phase is managed under GA or deep sedation. The patients who experience persistent delirium stay in the intensive care unit and hospital longer, ${ }^{97,98}$ have prolonged mechanical ventilation, ${ }^{98}$ incur more health care cost, ${ }^{99}$ and are at increased risk for dementia, institutionalization, and death after hospital discharge. ${ }^{100-103}$ One of the potential modifiable risk factors for perioperative delirium is the anesthesia "depth," characterized by electroencephalography monitoring (i.e., deeper anesthesia is associated with a higher incidence of delirium). ${ }^{104-109}$ However, whether keeping the patient under light to moderate sedation, instead of deep sedation or GA, during the pre-awake phase of $\mathrm{AC}$ is effective in preventing or reducing the incidence of emergence confusion/delirium remains to be determined. Whether the use of processed EEG anesthesia "depth" monitoring is beneficial during the anesthetic care for AC is another intriguing research topic. Finally, the effect of anesthetic agents on brain tumour progression or recurrence and patient survival should be prioritized in future research.

\section{Summary}

The improvement in anesthetic care has made a major contribution to the increasing popularity of AC. Thirteen aspects of the anesthetic management of patients undergoing AC have been discussed and summarized (Table 2). The majority of the technical 'pearls' are preference/opinion-based because of the lack of comparative evidence. Research is not always feasible when taking into account the scientific merits, priorities, and costs. Therefore, expert experience/opinion will continue to play an important role in clinical practice and the successful facilitation of AC.

Acknowledgements Support was provided solely from institutional and/or departmental sources. The authors thank Dr. Weiliang Zhang (Department of Anesthesiology, Affiliated Hospital of Shandong Traditional Chinese Medicine University, Jinan, Shandong Province, China) for his invaluable assistance with preparation of the figures.

Conflict of interest None declared.

Editorial responsibility This submission was handled by Dr. Hilary P. Grocott, Editor-in-Chief, Canadian Journal of Anesthesia.

Author contributions Lingzhong Meng, David L. McDonagh, Mitchel S. Berger, and Adrian W. Gelb contributed substantially to the conception and design of this review article. Lingzhong Meng and 
David L. McDonagh drafted the article. Lingzhong Meng, David L. McDonagh, Mitchel S. Berger, and Adrian W. Gelb critically revised the article.

Financial support and sponsorship None.

\section{References}

1. Horsley $V$. Remarks on ten consecutive cases of operations upon the brain and cranial cavity to illustrate the details and safety of the method employed. Br Med J 1887; 1: 863-5.

2. Penfield $W$, Boldrey E. Somatic motor and sensory representation in the cerebral cortex of man as studied by electrical stimulation. Brain 1937; 60: 3890443.

3. Penfield $W$. Combined regional and general anesthesia for craniotomy and cortical exploration. Part I. Neurosurgical considerations. Int Anesthesiol Clin 1986; 24: 1-11.

4. Ojemann G, Ojemann J, Lettich E, Berger M. Cortical language localization in left, dominant hemisphere. An electrical stimulation mapping investigation in 117 patients. J Neurosurg 1989; 71: 316-26.

5. Sanai N, Mirzadeh Z, Berger MS. Functional outcome after language mapping for glioma resection. N Engl J Med 2008; 358: 18-27.

6. Hervey-Jumper SL, Li J, Lau D, et al. Awake craniotomy to maximize glioma resection: methods and technical nuances over a 27-year period. J Neurosurg 2015; 123: 325-39.

7. Serletis D, Bernstein M. Prospective study of awake craniotomy used routinely and nonselectively for supratentorial tumors. J Neurosurg 2007; 107: 1-6.

8. Sacko O, Lauwers-Cances V, Brauge D, Sesay M, Brenner A, Roux FE. Awake craniotomy vs surgery under general anesthesia for resection of supratentorial lesions. Neurosurgery 2011; 68: 1192-8.

9. Surbeck W, Hildebrandt $G$, Duffau $H$. The evolution of brain surgery on awake patients. Acta Neurochir (Wien) 2015; 157: 77-84.

10. De Witt Hamer PC, Robles SG, Zwinderman AH, Duffau $H$, Berger MS. Impact of intraoperative stimulation brain mapping on glioma surgery outcome: a meta-analysis. J Clin Oncol 2012; 30: $2559-65$.

11. Brown T, Shah AH, Bregy A, et al. Awake craniotomy for brain tumor resection: the rule rather than the exception? J Neurosurg Anesthesiol 2013; 25: 240-7.

12. Nilsson E, Janssen P. Neurolept-analgesia - an alternative to general anesthesia. Acta Anaesthesiol Scand 1961; 5: 73-84.

13. Chen $G B$, Zhao YD, Xiao HR, et al. A study of acupuncture anesthesia in surgery on the anterior cranial fossa. J Tradit Chin Med 1984; 4: 189-96.

14. Archer DP, McKenna JM, Morin L, Ravussin P. Conscioussedation analgesia during craniotomy for intractable epilepsy: a review of 354 consecutive cases. Can J Anaesth 1988; 35: 33844.

15. Silbergeld DL, Mueller WM, Colley PS, Ojemann GA, Lettich E. Use of propofol (Diprivan) for awake craniotomies: technical note. Surg Neurol 1992; 38: 271-2.

16. Herrick IA, Craen RA, Gelb AW, et al. Propofol sedation during awake craniotomy for seizures: electrocorticographic and epileptogenic effects. Anesth Analg 1997; 84: 1280-4.

17. Huncke K, Van de Wiele B, Fried I, Rubinstein EH. The asleepawake-asleep anesthetic technique for intraoperative language mapping. Neurosurgery 1998; 42: 1312-6.
18. Soriano SG, Eldredge EA, Wang FK, et al. The effect of propofol on intraoperative electrocorticography and cortical stimulation during awake craniotomies in children. Paediatr Anaesth 2000; 10: 29-34.

19. Hans P, Bonhomme V, Born JD, Maertens de Noordhoudt A, Brichant JF, Dewandre $P Y$. Target-controlled infusion of propofol and remifentanil combined with bispectral index monitoring for awake craniotomy. Anaesthesia 2000; 55: 255-9.

20. Sahjpaul RL. Awake craniotomy: controversies, indications and techniques in the surgical treatment of temporal lobe epilepsy. Can J Neurol Sci 2000; S1: S55-63.

21. Berkenstadt H, Perel A, Hadani M, Unofrievich I, Ram Z. Monitored anesthesia care using remifentanil and propofol for awake craniotomy. J Neurosurg Anesthesiol 2001; 13: 246-9.

22. Fukaya C, Katayama Y, Yoshino A, Kobayashi K, Kasai M, Yamamoto $T$. Intraoperative wake-up procedure with propofol and laryngeal mask for optimal excision of brain tumour in eloquent areas. J Clin Neurosci 2001; 8: 253-5.

23. Herrick IA, Craen RA, Blume WT, Novick T, Gelb AW. Sedative doses of remifentanil have minimal effect on ECoG spike activity during awake epilepsy surgery. J Neurosurg Anesthesiol 2002; 14: 55-8.

24. Sarang A, Dinsmore J. Anaesthesia for awake craniotomyevolution of a technique that facilitates awake neurological testing. Br J Anaesth 2003; 90: 161-5.

25. Mack PF, Perrine K, Kobylarz E, Schwartz TH, Lien CA. Dexmedetomidine and neurocognitive testing in awake craniotomy. J Neurosurg Anesthesiol 2004; 16: 20-5.

26. Ard JL Jr, Bekker AY, Doyle WK. Dexmedetomidine in awake craniotomy: a technical note. Surg Neurol 2005; 63: 114-6.

27. Almeida AN, Tavares $C$, Tibano A, Sasaki S, Murata KN, Marino $R J r$. Dexmedetomidine for awake craniotomy without laryngeal mask. Arq Neuropsiquiatr 2005; 63: 748-50.

28. Keifer JC, Dentchev D, Little K, Warner DS, Friedman AH, Borel CO. A retrospective analysis of a remifentanil/propofol general anesthetic for craniotomy before awake functional brain mapping. Anesth Analg 2005; 101: 502-8.

29. Bulsara KR, Johnson J, Villavicencio AT. Improvements in brain tumor surgery: the modern history of awake craniotomies. Neurosurg Focus 2005; 18: e5.

30. Souter MJ, Rozet I, Ojemann JG, et al. Dexmedetomidine sedation during awake craniotomy for seizure resection: effects on electrocorticography. J Neurosurg Anesthesiol 2007; 19: 3844.

31. Frost EA, Booij LH. Anesthesia in the patient for awake craniotomy. Curr Opin Anaesthesiol 2007; 20: 331-5.

32. See JJ, Lew TW, Kwek TK, et al. Anaesthetic management of awake craniotomy for tumour resection. Ann Acad Med Singapore 2007; 36: 319-25.

33. Piccioni F, Fanzio M. Management of anesthesia in awake craniotomy. Minerva Anestesiol 2008; 74: 393-408.

34. Olsen KS. The asleep-awake technique using propofolremifentanil anaesthesia for awake craniotomy for cerebral tumours. Eur J Anaesthesiol 2008; 25: 662-9.

35. Bonhomme $V$, Franssen $C$, Hans $P$. Awake craniotomy. Eur $\mathrm{J}$ Anaesthesiol 2009; 26: 906-12.

36. Bilotta $F$, Rosa G. 'Anesthesia' for awake neurosurgery. Curr Opin Anaesthesiol 2009; 22: 560-5.

37. Conte V, Magni L, Songa V, et al. Analysis of propofol/ remifentanil infusion protocol for tumor surgery with intraoperative brain mapping. J Neurosurg Anesthesiol 2010; 22: $119-27$.

38. Erickson KM, Cole DJ. Anesthetic considerations for awake craniotomy for epilepsy and functional neurosurgery. Anesthesiol Clin 2012; 30: 241-68. 
39. Hansen E, Seemann $M$, Zech $N$, Doenitz $C$, Luerding $R$, Brawanski A. Awake craniotomies without any sedation: the awake-awake-awake technique. Acta Neurochir (Wien) 2013; 155: $1417-24$.

40. Bilotta F, Guerra C, Rosa G. Update on anesthesia for craniotomy. Curr Opin Anaesthesiol 2013; 26: 517-22.

41. Garavaglia $M M$, Das $S$, Cusimano $M D$, et al. Anesthetic approach to high-risk patients and prolonged awake craniotomy using dexmedetomidine and scalp block. J Neurosurg Anesthesiol 2014; 26: 226-33.

42. Cherng $C H, W u Z F$, Lin BF. A modified nasopharyngeal tube for awake craniotomy. J Neurosurg Anesthesiol 2016; 28: 275-7.

43. Sivasankar C, Schlichter RA, Baranov D, Kofke WA. Awake craniotomy: a new airway approach. Anesth Analg 2016; 122: 509-11.

44. Dilmen OK, Akcil EF, Oguz A, Vehid H, Tunali Y. Comparison of conscious sedation and asleep-awake-asleep techniques for awake craniotomy. J Clin Neurosci 2017; 35: 30-4.

45. Stevanovic A, Rossaint R, Veldeman M, Bilotta F, Coburn M. Anaesthesia management for awake craniotomy: systematic review and meta-analysis. PLoS One 2016; 11: e0156448.

46. Meng L, Weston SD, Chang EF, Gelb AW. Awake craniotomy in a patient with ejection fraction of $10 \%$ : considerations of cerebrovascular and cardiovascular physiology. J Clin Anesth 2015; 27: 256-61.

47. Meng L, Han SJ, Rollins MD, Gelb AW, Chang EF. Awake brain tumor resection during pregnancy: decision making and technical nuances. J Clin Neurosci 2016; 24: 160-2.

48. Klimek M, Verbrugge SJ, Roubos $S$, van der Most E, Vincent AJ, Klein J. Awake craniotomy for glioblastoma in a 9-year-old child. Anaesthesia 2004; 59: 607-9.

49. Lin N, Han R, Zhou J, Gelb AW. Mild sedation exacerbates or unmasks focal neurologic dysfunction in neurosurgical patients with supratentorial brain mass lesions in a drug-specific manner. Anesthesiology 2016; 124: 598-607.

50. Gignac E, Manninen PH, Gelb AW. Comparison of fentanyl, sufentanil and alfentanil during awake craniotomy for epilepsy. Can J Anaesth 1993; 40(5 Pt 1): 421-4.

51. Herrick IA, Craen RA, Gelb AW, et al. Propofol sedation during awake craniotomy for seizures: patient-controlled administration versus neurolept analgesia. Anesth Analg 1997; 84: 1285-91.

52. Manninen PH, Balki $M$, Lukitto $K$, Bernstein $M$. Patient satisfaction with awake craniotomy for tumor surgery: a comparison of remifentanil and fentanyl in conjunction with propofol. Anesth Analg 2006; 102: 237-42.

53. Merchant RN, Dobson G. Special announcement: guidelines to the practice of anesthesia - revised edition 2016. Can J Anesth 2016; 63: 12-5.

54. Meng L, Berger MS, Gelb AW. The potential benefits of awake craniotomy for brain tumor resection: an anesthesiologist's perspective. J Neurosurg Anesthesiol 2015; 27: 310-7.

55. Girvin JP. Neurosurgical considerations and general methods for craniotomy under local anesthesia. Int Anesthiol Clin 1986; 24: 89-114.

56. Chaki T, Sugino $S$, Janicki $P K$, et al. Efficacy and safety of a lidocaine and ropivacaine mixture for scalp nerve block and local infiltration anesthesia in patients undergoing awake craniotomy. J Neurosurg Anesthesiol 2016; 28: 1-5.

57. Song $J, L i L, Y u$ P, Gao T, Liu K. Preemptive scalp infiltration with $0.5 \%$ ropivacaine and $1 \%$ lidocaine reduces postoperative pain after craniotomy. Acta Neurochir (Wien) 2015; 157: 993-8.

58. Law-Koune JD, Szekely B, Fermanian C, Peuch C, Liu N, Fischler $M$. Scalp infiltration with bupivacaine plus epinephrine or plain ropivacaine reduces postoperative pain after supratentorial craniotomy. J Neurosurg Anesthesiol 2005; 17: $139-43$.
59. Geze S, Yilmaz AA, Tuzuner F. The effect of scalp block and local infiltration on the haemodynamic and stress response to skull-pin placement for craniotomy. Eur J Anaesthesiol 2009; 26: 298-303.

60. Snyder GL, Greenberg S. Effect of anaesthetic technique and other perioperative factors on cancer recurrence. $\mathrm{Br} \mathrm{J}$ Anaesth 2010; 105: 106-15.

61. Byrne K, Levins KJ, Buggy DJ. Can anesthetic-analgesic technique during primary cancer surgery affect recurrence or metastasis? Can J Anesth 2016; 63: 184-92.

62. Mao L, Lin S, Lin J. The effects of anesthetics on tumor progression. Int J Physiol Pathophysiol Pharmacol 2013; 5: 1-10.

63. Chen WK, Miao $\mathrm{CH}$. The effect of anesthetic technique on survival in human cancers: a meta-analysis of retrospective and prospective studies. PLoS ONE 2013; 8: e56540.

64. Meserve JR, Kaye AD, Prabhakar A, Urman RD. The role of analgesics in cancer propagation. Best Pract Res Clin Anaesthesiol 2014; 28: 139-51.

65. Cata JP, Hernandez M, Lewis VO, Kurz A. Can regional anesthesia and analgesia prolong cancer survival after orthopaedic oncologic surgery? Clin Orthop Relat Res 2014; 472: 1434-41.

66. Cakmakkaya OS, Kolodzie K, Apfel CC, Pace NL. Anaesthetic techniques for risk of malignant tumour recurrence. Cochrane Database Syst Rev 2014; 11: CD008877.

67. Neal JM, Bernards CM, Butterworth JF 4th, et al. ASRA practice advisory on local anesthetic systemic toxicity. Reg Anesth Pain Med 2010; 35: 152-61.

68. Bissonnette B, Swan H, Ravussin P, Un V. Neuroleptanesthesia: current status. Can J Anaesth 1999; 46: 154-68.

69. Wigmore TJ, Mohammed K, Jhanji S. Long-term survival for patients undergoing volatile versus iv anesthesia for cancer surgery: A Retrospective Analysis. Anesthesiology 2016; 124: 69-79.

70. Melamed R, Bar-Yosef S, Shakhar G, Shakhar K, Ben-Eliyahu S. Suppression of natural killer cell activity and promotion of tumor metastasis by ketamine, thiopental, and halothane, but not by propofol: mediating mechanisms and prophylactic measures. Anesth Analg 2003; 97: 1331-9.

71. Shapiro J, Jersky J, Katzav S, Feldman M, Segal S. Anesthetic drugs accelerate the progression of postoperative metastases of mouse tumors. J Clin Invest 1981; 68: 678-85.

72. Katzav S, Shapiro J, Segal S, Feldman M. General anesthesia during excision of a mouse tumor accelerates postsurgical growth of metastases by suppression of natural killer cell activity. Isr J Med Sci 1986; 22: 339-45.

73. Inada T, Kubo K, Kambara T, Shingu K. Propofol inhibits cyclooxygenase activity in human monocytic THP-1 cells. Can J Anesth 2009; 56: 222-9.

74. Kambara T, Inada T, Kubo K, Shingu K. Propofol suppresses prostaglandin $\mathrm{E}(2)$ production in human peripheral monocytes. Immunopharmacol Immunotoxicol 2009; 31: 117-26.

75. Inada T, Yamanouchi Y, Jomura S, et al. Effect of propofol and isoflurane anaesthesia on the immune response to surgery. Anaesthesia 2004; 59: 954-9.

76. Kushida A, Inada T, Shingu $K$. Enhancement of antitumor immunity after propofol treatment in mice. Immunopharmacol Immunotoxicol 2007; 29: 477-86.

77. Inada $T$, Kubo K, Shingu $K$. Possible link between cyclooxygenase-inhibiting and antitumor properties of propofol. J Anesth 2011; 25: 569-75.

78. Tavare AN, Perry NJ, Benzonana LL, Takata M, Ma D. Cancer recurrence after surgery: direct and indirect effects of anesthetic agents. Int J Cancer 2012; 130: 1237-50.

79. Huang H, Benzonana LL, Zhao H, et al. Prostate cancer cell malignancy via modulation of HIF-1 $\alpha$ pathway with isoflurane 
and propofol alone and in combination. Br J Cancer 2014; 111 : 1338-49.

80. Enlund M, Berglund A, Andreasson K, Cicek C, Enlund A, Bergkvist $L$. The choice of anaesthetic-sevoflurane or propofoland outcome from cancer surgery: a retrospective analysis. Ups J Med Sci 2014; 119: 251-61.

81. Rama-Maceiras $P$, Ferreira TA, Molíns $N$, Sanduende $Y$, Bautista AP, Rey T. Less postoperative nausea and vomiting after propofol + remifentanil versus propofol + fentanyl anaesthesia during plastic surgery. Acta Anaesthesiol Scand 2005; 49: 305-11.

82. Goettel N, Bharadwaj S, Venkatraghavan L, Mehta J, Bernstein $M$, Manninen $P H$. Dexmedetomidine vs propofol-remifentanil conscious sedation for awake craniotomy: a prospective randomized controlled trial. Br J Anaesth 2016; 116: 811-21.

83. Bilotta $F$, Stazi E, Delfini R, Rosa $G$. Language testing during awake "anesthesia" in a bilingual patient with brain lesion adjacent to Wernicke's area. Anesth Analg 2011; 112: 938-9.

84. Funk W, Hollnberger H, Geroldinger J. Physostigmine and anaesthesia emergence delirium in preschool children: a randomized blinded trial. Eur J Anaesthesiol 2008; 25: 37-42.

85. Brown DV, Heller F, Barkin R. Anticholinergic syndrome after anesthesia: a case report and review. Am J Ther 2004; 11: 144-53.

86. Mercadante S, Serretta $R$, Casuccio A. Effects of caffeine as an adjuvant to morphine in advanced cancer patients. A randomized, double-blind, placebo-controlled, crossover study. J Pain Symptom Manage 2001; 21: 369-72.

87. Iirola $T$, Ihmsen $H$, Laitio $R$, et al. Population pharmacokinetics of dexmedetomidine during long-term sedation in intensive care patients. Br J Anaesth 2012; 108: 460-8.

88. Nossek E, Matot I, Shahar T, et al. Intraoperative seizures during awake craniotomy: incidence and consequences: analysis of 477 patients. Neurosurgery 2013; 73: 135-40.

89. Skucas AP, Artru AA. Anesthetic complications of awake craniotomies for epilepsy surgery. Anesth Analg 2006; 102: 882-7.

90. Taylor MD, Bernstein M. Awake craniotomy with brain mapping as the routine surgical approach to treating patients with supratentorial intraaxial tumors: a prospective trial of 200 cases. J Neurosurg 1999; 90: 35-41.

91. Boulton M, Bernstein M. Outpatient brain tumor surgery: innovation in surgical neurooncology. J Neurosurg 2008; 108: 649-54.

92. Venkatraghavan L, Bharadwaj S, Au K, Bernstein M, Manninen $P$. Same-day discharge after craniotomy for supratentorial tumour surgery: a retrospective observational single-centre study. Can J Anesth 2016; 63: 1245-57.

93. Flexman AM, Meng L, Gelb AW. Outcomes in neuroanesthesia: what matters most? Can J Anesth 2016; 63: 205-11.

94. Sharma PT, Sieber FE, Zakriya KJ, et al. Recovery room delirium predicts postoperative delirium after hip-fracture repair. Anesth Analg 2005; 101: 1215-20.

95. Neufeld KJ, Leoutsakos JM, Sieber FE, et al. Outcomes of early delirium diagnosis after general anesthesia in the elderly. Anesth Analg 2013; 117: 471-8.
96. Card E, Pandharipande P, Tomes $C$, et al. Emergence from general anaesthesia and evolution of delirium signs in the postanaesthesia care unit. Br J Anaesth 2015; 115: 411-7.

97. Ely EW, Gautam S, Margolin R, et al. The impact of delirium in the intensive care unit on hospital length of stay. Intensive Care Med 2001; 27: 1892-900.

98. Stransky $M$, Schmidt $C$, Ganslmeier $P$, et al. Hypoactive delirium after cardiac surgery as an independent risk factor for prolonged mechanical ventilation. J Cardiothorac Vasc Anesth 2011; 25: 968-74.

99. Leslie DL, Marcantonio ER, Zhang Y, Leo-Summers L, Inouye $S K$. One-year health care costs associated with delirium in the elderly population. Arch Intern Med 2008; 168: 27-32.

100. Witlox J, Eurelings LS, de Jonghe JF, Kalisvaart KJ, Eikelenboom $P$, van Gool WA. Delirium in elderly patients and the risk of postdischarge mortality, institutionalization, and dementia: a meta-analysis. JAMA 2010; 304: 443-51.

101. Maldonado JR. Delirium in the acute care setting: characteristics, diagnosis and treatment. Crit Care Clin 2008; 24: 657-722.

102. Robinson TN, Raeburn CD, Tran ZV, Angles EM, Brenner LA, Moss $M$. Postoperative delirium in the elderly: risk factors and outcomes. Ann Surg 2009; 249: 173-8.

103. Saczynski JS, Marcantonio ER, Quach L, et al. Cognitive trajectories after postoperative delirium. N Engl J Med 2012; 367: 30-9.

104. Sieber FE, Zakriya KJ, Gottschalk A, et al. Sedation depth during spinal anesthesia and the development of postoperative delirium in elderly patients undergoing hip fracture repair. Mayo Clin Proc 2010; 85: 18-26.

105. Chan MT, Cheng BC, Lee TM, Gin T, CODA Trial Group. BISguided anesthesia decreases postoperative delirium and cognitive decline. J Neurosurg Anesthesiol 2013; 25: 33-42.

106. Radtke FM, Franck $M$, Lendner J, Kruger S, Wernecke KD, Spies $C D$. Monitoring depth of anaesthesia in a randomized trial decreases the rate of postoperative delirium but not postoperative cognitive dysfunction. $\mathrm{Br}$ J Anaesth 2013; 110(Suppl 1): i98-105.

107. Andresen JM, Girard TD, Pandharipande PP, Davidson MA, Ely EW, Watson PL. Burst suppression on processed electroencephalography as a predictor of postcoma delirium in mechanically ventilated ICU patients. Crit Care Med 2014; 42: 2244-51.

108. Soehle M, Dittmann A, Ellerkmann RK, Baumgarten $G$, Putensen $C$, Guenther $U$. Intraoperative burst suppression is associated with postoperative delirium following cardiac surgery: a prospective, observational study. BMC Anesthesiol 2015; 15: 61 .

109. Fritz BA, Kalarickal PL, Maybrier HR, et al. Intraoperative electroencephalogram suppression predicts postoperative delirium. Anesth Analg 2016; 122: 234-42. 